\title{
Post-surgical heart block
}

\section{Report of a case with bilateral bundle-branch block and changing rhythms}

\author{
Robert T. Potter, Lena Liu, and Edwin P. Maynard, Jr. \\ From the Departments of Surgery, Pediatrics, and Medicine, The Brooklyn-Cumberland \\ Medical Center, 121 DeKalb Avenue, Brooklyn, New York I I20I, U.S.A.
}

A case of postoperative bilateral bundle-branch block is described. After complete correction of tetrad of Fallot, the patient showed varying degrees of heart block for the first I8 months after operation, normal sinus rhythm for the next year, and then a reversion to intermittent complete heart block. A pacemaker was implanted three years after operation when symptoms appeared in conjunction with periods of slow heart rate, and when the implications of postoperative bilateral bundle-branch block were appreciated. To date, this conduction disturbance has been recognized in arteriosclerotic heart disease, but, with the exception of one report, has not been discussed in relation to the surgical repair of ventricular septal defects. When bilateral bundle-branch block develops after heart operation, it is probably best to initiate electrical pacing of the heart immediately.

Bilateral bundle-branch block after closure of a ventricular septal defect has not been described until recently (Kulbertus, Coyne, and Hallidie-Smith, I969). It results from operative damage to the right bundle-branch and to the superior division of the left bundle-branch, with sparing of the inferior division. Anatomically, this damage occurs at the posterior-inferior margin of the ventricular septal defect; it may result from haematoma, infarction, or suture penetration. The usual electrocardiographic characteristics are: (I) right bundle-branch block and obvious left axis deviation, or (2) alternating complexes of left bundle-branch block and right bundlebranch block. Clinically, the patient may manifest a bizarre form of postoperative intermittent complete heart block. A case history will illustrate the vicissitudes of the changing heart rhythms and point up the problems of management.

\section{Case history}

On 24 July 1966, a 12-year-old schoolboy was admitted to The Brooklyn Hospital for surgical correction of tetrad of Fallot. On admission he was a slim pale boy weighing $27 \mathrm{~kg}$. and showing cyanosis of the lips and nail beds and clubbing of the fingers. Examination of the chest showed clear lung fields. The point of maximum impulse was in the fifth left interspace and the midclavicular line. The second heart sound was loud and single. A palpable thrill and a grade 4/6 systolic murmur were present over the left praecordium. The liver and spleen were not palpable and there was no oedema. The electrocardiogram showed normal conduction, right axis deviation, and right ventricular hypertrophy.

At operation on 27 July 1966, a bicuspid pulmonary valve was found, with partial fusion of the commissures, infundibular pulmonary stenosis, and a high ventricular septal defect $I .5 \mathrm{~cm}$. in diameter. The correction consisted of opening the pulmonary valve commissures, resecting infundibular trabeculae and a portion of the crista supraventricularis, and closing the ventricular septal defect with a prosthetic patch. When cardiopulmonary bypass was discontinued the heart beat slowly and ineffectively, and the electrocardiogram showed atrioventricular dissociation. Accordingly, bypass was reinstituted, the right ventriculotomy was opened, and the six sutures closest to the conduction bundle were removed. An extension was sutured to the patch, and the free edge of the extended patch was sutured to the posterior margin of the ventricular septal defect with I I superficially-placed sutures. At this time an area of haematoma was noted in the septum near the posteroinferior corner of the defect. When cardiopulmonary bypass was discontinued for the second time, the heart beat was stronger and the electrocardiographic monitor showed a rate of 72 beats a minute with some evidence of atrioventricular conduction. Pacemaker wires 


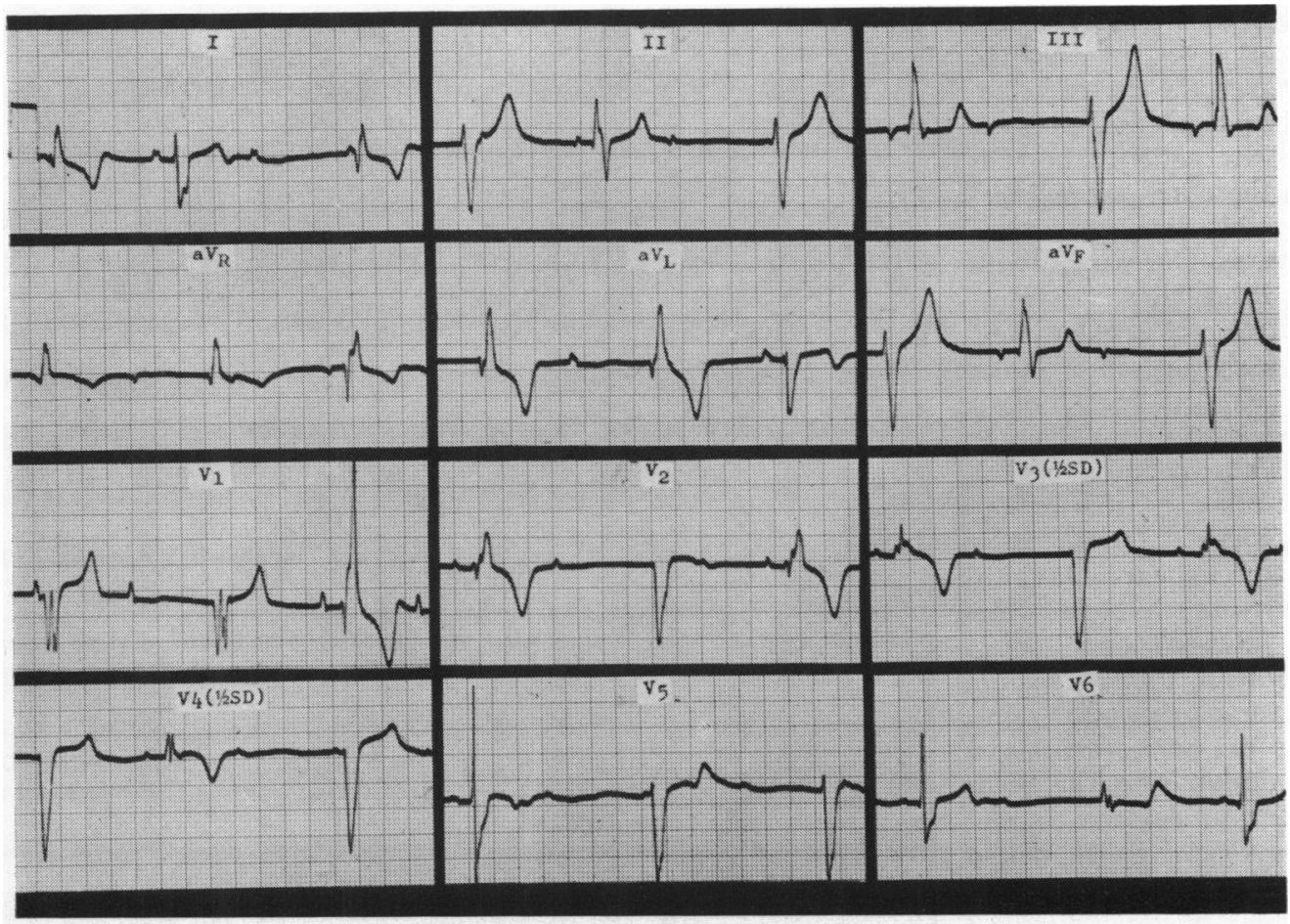

FIG. I Electrocardiogram taken 18 months after operation showing right bundle-branch complexes of alternating right and left ventricular origin. The left ventricular complexes are conducted beats. This tracing illustrates bilateral bundle-branch block.

were placed in the right ventricular wall and the chest was closed.

During the first II postoperative days the heart rate varied from 50 to 90 beats a minute, and the electrocardiogram showed complete atrioventricalar dissociation caused by atrioventricular block and evidence of anteroseptal infarction.

On the 12th postoperative day regular sinus rhythm with right bundle-branch block pattern first appeared on the electrocardiogram. Normal conduction thereafter alternated with a variety of rhythms, including 2: I block with right bundlebranch block pattern and apparent third degree heart block with shifting right and left bundlebranch block types of complexes (Fig. I), until December 1967, when the heart returned to normal sinus rhythm for a full year.

In December 1968, coincident with a severe respiratory infection (Hong Kong influenza), the patient's heart rate dropped from about 72 beats a minute to 40 beats a minute. The electrocardiogram showed an atrial rate of 95, a ventricular rate 40 a minute, and ventricular complexes of

1 alternating right and left ventricular origin. The right bundle-branch block complexes were conducted beats (as in Fig. I). Thus the tracing showed the combination of right bundle-branch block and incomplete left bundle-branch block which typifies bilateral bundle-branch block.

Since the autumn of 1966 the patient has attended school regularly and has participated in mild athletics including bicycling and bowling. His scholastic record is good. Electrocardiograms have recorded a variety of cardiac rhythms (Fig. 2). Symptoms related to a slow heart rate have been shortness of breath after climbing three flights of stairs and, on five occasions when the heart rate dropped to 36 to 40 range, praecordial chest pain of a few minutes' duration. There have been no Adams-Stokes attacks.

On 2r May 1969, a Medtronic ${ }^{1}$ demand cardiac pacemaker was implanted, and to date there have been no further symptoms.

\section{Discussion}

The usual type of postoperative complete heart block, which results from damage to the common conduction bundle of His, may or may not be permanent. In 30 to 75 per cent of cases complete heart block clears completely (Lillehei et al., 1963), but if reversion to regular sinus rhythm does not occur within 6 weeks of operation it is not likely to occur at all (Lillehei et al., 1963; McGoon, Ongley, and Kirklin, 1964).

${ }_{1}^{1}$ Medtronic, Inc., Minneapolis, Minnesota 55418, U.S.A. 
Lillehei et al. (1963) have observed that persistent complete heart block, in which no conducted beats are seen on the electrocardiogram at any time in the postoperative period, is usually fatal unless the patient's heart is paced electrically. On the other hand, intermittent complete heart block enjoys a relatively favourable prognosis. Our patient with intermittent complete heart block was most unusual in having reversion to regular sinus rhythm 18 months after operation, then return of intermittent complete heart block a year later. The continuing and unpredictable change in rhythms was attributed to surgical injury of both bundle-branches, that is, bilateral bundle-branch block.

Historically, the electrocardiographic findings of bilateral bundle-branch block were described by Wilson, Johnston, and Barker (1934) in association with arteriosclerotic heart disease. The same changes, right bundle-branch block in the praecordial leads and obvious left axis deviation in the limb leads, were correlated with damage to the right bundle-branch by Grant (1956). Bernstein, Samet, and Litwak (I960) have reported on experimental bilateral bundlebranch block, and Lasser, Haft, and Friedberg (I968) have pointed out the relation of right bundle-branch block and obvious left axis deviation to complete heart block and syncope, noting that in arteriosclerotic heart disease these electrocardiographic findings are the most common precursor of complete heart block. They mentioned also that the combination of right bundle-branch block and conspicuous left axis deviation is well known in congenital heart disease, and is seen in a majority of endocardial cushion defects.

Kulbertus et al. (1969) have reported an incidence of surgically acquired bilateral bundle-branch block of 8.7 per cent among I40 patients operated upon for ventricular septal defect and 136 patients for tetrad of Fallot at Hammersmith Hospital over a royear period. Postoperative electrocardiograms showed right bundle-branch block and obvious left axis deviation. Since these electrocardiographic features were present before operation in all of 6 surgically corrected atrioventricular canal defects, the authors refer to the 'atrioventricular canal type of electrocardiogram', but, in fact, describe bilateral bundle-branch block.

In our patient the electrocardiographic findings of alternating beats of right bundlebranch block and left bundle-branch block are another expression of the same conduction abnormality. Kulbertus et al. (1969) conclude that since excitation of the left ventricle in

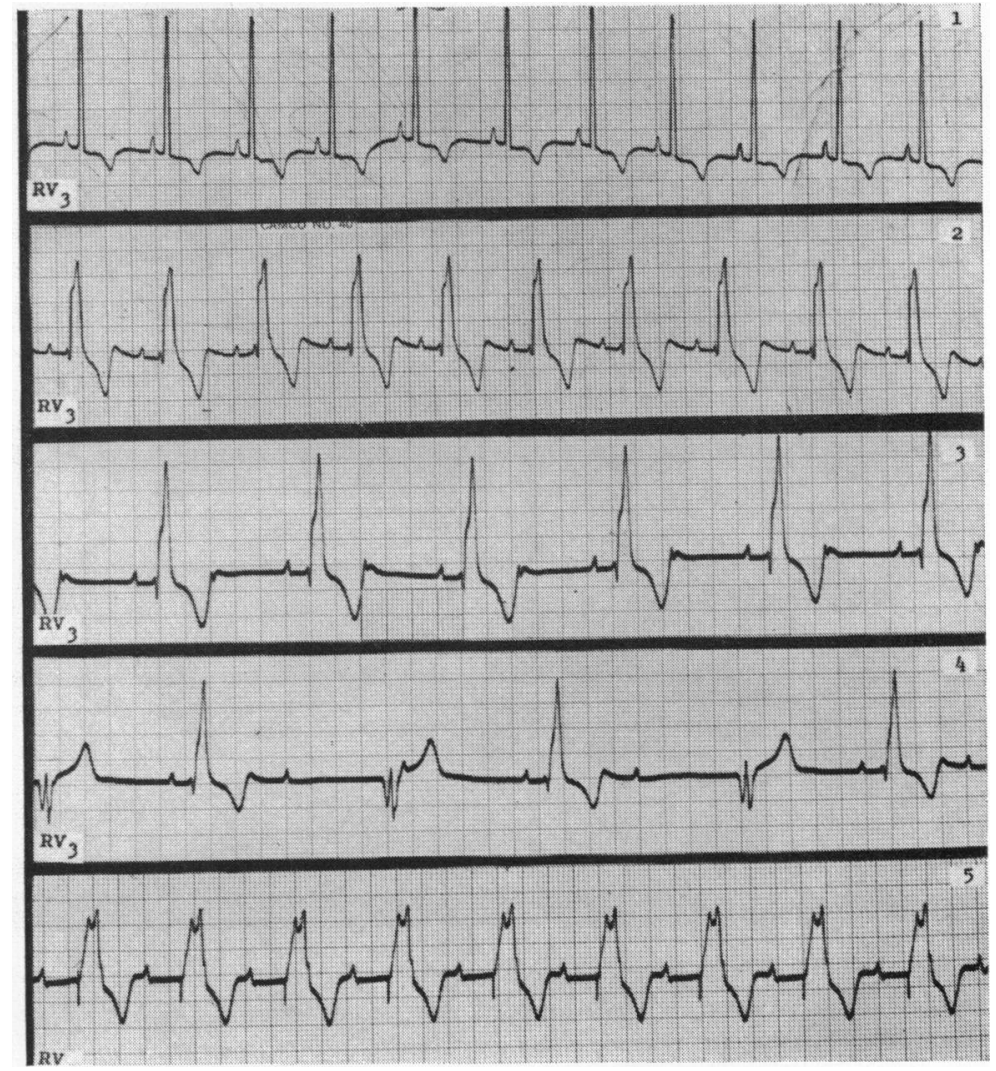

FIG. 2 Summary of various cardiac rhythms

before and after operation: (I) Preoperative

tracing showing normal sinus rhythm; (2)

postoperative tracing showing normal sinus rhythm with right bundle-branch block (first degree heart block); (3) postoperative tracing showing two-to-one block with right bundlebranch block; (4) postoperative tracing showing bilateral bundle-branch block manifested by alternating $R B B B$ and $L B B B$ complexes; and (5) postoperative tracing showing regular pacing by demand pacemaker.

bilateral bundle-branch block depends on the conduction of the inferior division of the left bundle-branch, 'complete atrioventricular dissociation represents a permanent threat, especially after sugery. Indeed, this complication occurred in the postoperative period of I5 out of the 45 patients ( 33 per cent) who showed the atrioventricular canal type of electrocardiogram either before or after surgery.'

In the present case postoperative bilateral bundle-branch block was associated with intermittent complete heart block due to variable conduction along the remaining atrioventricular pathway, the inferior division 
of the left bundle-branch. The symptoms associated with a slow heart rate and the possibility of Adams-Stokes seizures eventually led us to place an implantable demand cardiac pacemaker. Because of recent evidence that bilateral bundle-branch block occurring after acute myocardial infarction carries a grave prognosis (Stock and Macken, 1968; William J. Grace, 1969, personal communication), it seems wise to view this lesion with concern when it develops after surgical correction of a congenital heart defect and to consider immediate electrical pacing.

The authors are indebted to Dr. M. Irene Ferrer for her assistance in the management of this case.

\section{References}

Bernstein, W. H., Samet, P., and Litwak, R. S. (1960). Experimental bilateral bundle branch block. American fournal of Cardiology, 5, 799.

Grant, R. P. (1956). Left axis deviation: an electro- cardiographic-pathologic correlation study. Circulation, 14, 233.

Kulbertus, H. E., Coyne, J. J., and Hallidie-Smith, K. A. (1969). Conduction disturbances before and after surgical closure of ventricular septal defect. American Heart Fournal, 77, 123.

Lasser, R. P., Haft, J. I., and Friedberg, C. K. (I968). Relationship of right bundle-branch block and marked left axis deviation (with left parietal or peri-infarction block) to complete heart block and syncope. Circulation, 37, 429.

Lillehei, C. W., Sellers, R. D., Bonnabeau, R. C., Jr., and Eliot, R. S. (1963). Chronic postsurgical complete heart block with particular reference to prognosis, management, and a new P-wave pacemaker. fournal of Thoracic and Cardiovascular Surgery, 46, 436.

McGoon, D. C., Ongley, P. A., and Kirklin, J. W. (1964). Surgical heart block. American Fournal of Medicine, 37, 749.

Stock, R. J., and Macken, D. L. (1968). Observations on heart block during continuous electrocardiographic monitoring in myocardial infarction. Circulation, 38, 993.

Wilson, F. N., Johnston, F. D., and Barker, P. S. (1934). Electrocardiograms of an unusual type in right bundle-branch block. American Heart fournal, 9, 472. 